\title{
Randomised controlled study of early use of inhaled corticosteroid in preterm infants with respiratory distress syndrome
}

\author{
T F Fok, K Lam, M Dolovich, P C Ng, W Wong, K L Cheung, K W So
}

\begin{abstract}
Aim-To investigate the therapeutic efficacy of inhaled fluticasone propionate, started on day 1 of age, on ventilated preterm infants with respiratory distress syndrome.

Methods-Starting within 24 hours of age, ventilated preterm infants (gestation $<32$ weeks, birthweight $<1.5 \mathrm{~kg}$ ) with respiratory distress syndrome were given a 14 day course (two puffs, 12 hourly) of either fluticasone propionate $(250 \mu \mathrm{g} / \mathrm{puff})$ (group 1 , $\mathbf{n}=27$ ) or placebo (group $2, n=26$ ) with a metered dose inhaler-spacer device. Response to treatment was assessed by the rate of successful extubation by days 7 and 14 of age, changes in respiratory system mechanics, death, occurrence of chronic lung disease, and other neonatal complications.
\end{abstract}

Results-More infants in the treatment group were successfully extubated by 14 days of age than those in the placebo group $(17 / 27$ vs $8 / 26 ; p=0.038)$. The treated infants also showed a more significant improvement in respiratory system compliance during the first $\mathbf{1 4}$ days of life. The two groups, however, did not differ significantly in their need for systemic steroids after day 14 of age, death, or the occurrence of chronic lung disease. The treatment was not associated with any increase in neonatal complications, including those attributable to steroid induced side effects.

Conclusion-These results provide preliminary evidence that early treatment with inhaled corticosteroids may be beneficial to ventilated preterm infants with respiratory distress. Further study of its use in a large scale randomised trial is warranted.

(Arch Dis Child Fetal Neonatal Ed 1999;80:F203-F208)

Keywords: respiratory distress syndrome; mechanical ventilation; corticosteroid; aerosol; fluticasone propionate

Department of

Medicine

McMaster University

Medical Centre

Hamilton

Ontario

Canada

M Dolovich

Correspondence to:

Dr T F Fok

Email:taifaifok@

cuhk.edu.hktaifaifok@

cuhk.edu.hk

Accepted 26 October 1998 tration of systemic dexamethasone within the first day of life has been associated with a more rapid improvement in respiratory status, earlier extubation, ${ }^{3-5}$ and reduction of CLD. ${ }^{4}$ There is evidence that preterm infants younger than 2 weeks of age are more prone to nosocomial infections and impaired brain development as a result of corticosteroid treatment. ${ }^{67}$ There are also concerns that the early treatment regimen will unnecessarily subject infants who are not destined to develop CLD to the risk of other steroid induced complications, such as hypertension, hyperglycaemia, growth impairment, and suppression of hypothalamic-pituitaryadrenal functions. By delivering the medication directly into the lungs as an aerosol, the dose and the risks can be reduced..$^{8-11}$ In preterm infants with established CLD inhaled corticosteroid can lessen their respiratory symptoms, ${ }^{12}$ improve their lung function, ${ }^{8-12}$ reduce their need for systemic steroids, ${ }^{9}$ and facilitate earlier extubation. ${ }^{13}$ This randomised study was carried out to evaluate the therapeutic efficacy of inhaled fluticasone propionate in the early treatment of ventilated preterm infants with RDS.

\section{Methods}

The study was approved by the Clinical Research Ethics Committee of the Chinese University of Hong Kong.

Inborn preterm infants admitted consecutively into our neonatal intensive care unit for the treatment of RDS were considered eligible for the study if they satisfied the following criteria: gestation $<32$ weeks; birthweight $<1.5$ $\mathrm{kg}$; requirement for mechanical ventilation; and parental consent to the study. All the infants were given two doses ( $5 \mathrm{ml} / \mathrm{kg}$ per dose) of intratracheal synthetic surfactant (Exosurf, Burroughs Wellcome Corporation, UK) 12 hours apart. The first dose was given within 1 hour of birth. The infant was enrolled if a blood gas obtained between 6 to 10 hours after the second dose of surfactant (19 to 23 hours after birth) showed an arterial $\mathrm{PO}_{2}$ :alveolar $\mathrm{PO}_{2}$ ratio of $<0.25$. Alveolar $\mathrm{PO}_{2}\left(\mathrm{PAO}_{2}\right)$ was calculated from the alveolar gas equation $\mathrm{PaO}_{2}$ $=\mathrm{PIO}_{2}-\mathrm{PaCO}_{2} / \mathrm{R}+\mathrm{PaCO}_{2} \times \mathrm{FI} \mathrm{O} \times(1-) / \mathrm{R}$ where $\mathrm{PIO}_{2}$ is the partial pressure of oxygen in the inspired gas and equals the difference between the atmospheric pressure $(760 \mathrm{~mm}$ $\mathrm{Hg}$ or $101.3 \mathrm{kPa}$ ) and the saturated water vapour pressure $(47 \mathrm{~mm} \mathrm{Hg}$ or $6.3 \mathrm{kPa}$ ), $\mathrm{PaCO}_{2}$ is the arterial carbon dioxide tension and $\mathrm{R}$ is the respiratory quotient and equals 0.8. Infants who were dying and those with 
significant congenital malformation were excluded. The infants enrolled were randomised by computer generated random numbers into treatment (group 1) and control groups (group 2 ); allocation to the groups was carried out by opening opaque, sealed envelopes. The calculation of the required number of infants in each group was based on a previous report on the early use of systemic dexamethasone which showed that successful extubation at 2 weeks of age was accomplished in $57 \%$ of the treated group and in $28 \%$ in the placebo group. ${ }^{3} \mathrm{~A}$ sample size of 26 in each group would result in a power of 0.8 for detecting a difference of this size with an $\alpha$ error of $<0.05$.

All the infants were given intravenous penicillin and netilmicin shortly after birth, after a blood count and blood culture specimens were obtained. The antibiotics were discontinued after three days if the infants showed no sign of sepsis and the blood culture remained negative. All infants were continuously monitored for their heart rate, respiratory rate, and transcutaneous oxygen saturation $\left(\mathrm{SaO}_{2}\right)$. Blood pressure was monitored continuously through an indwelling arterial catheter when available, or hourly using the oscillometric method (Dinamap XL Vital Signs Monitor, Johnson and Johnson Medical Inc, USA). Capillary blood glucose concentration was tested four times daily using the strip method (Haemo-Glukotest, Boehringer Mannheim, GmbH, Germany). True blood glucose was measured when the Haemo-Glukotest showed the presence of hyperglycaemia (blood glucose $>7 \mathrm{mmol} / \mathrm{l}$ ).

Each infant in group $1(n=27)$ was given two puffs of fluticasone by metered dose inhaler (MDI) (Flixotide; Glaxo, UK; $250 \mu \mathrm{g}$ per puff), and in group $2(n=26)$ two puffs of placebo provided by the same manufacturer, 12 hourly for two weeks. The first dose was given within 24 hours of birth. The label on the MDI canisters had been removed so as to conceal the identity of the contents.

Aerosol delivery was carried out by an investigator not involved in the clinical management of the patients or data collection. Immediately before aerosol delivery, an MV15s Aerochamber was inserted between the Y-connector of the ventilator circuit and endotracheal tube. After suctioning of the endotracheal tube, two puffs of the aerosol (fluticasone or placebo, as appropriate) were actuated into the spacer one minute apart immediately before the inspiratory phase of a ventilator generated breath. The MDI canister was vigorously shaken for at least 10 seconds before each actuation. The spacer was removed one minute after the second puff.

Extubation was considered when the $\mathrm{FIO}_{2}$ and ventilator rate were decreased to $<0.4$ and $\leqslant 10$ breaths a minute, respectively. The decision to extubate was made by the attending neonatologists who were blinded to the study protocol and the nature of the aerosol given to the infants. After the endotracheal tube was removed oxygen was administered via a head box at a concentration $10 \%$ higher than that of the ventilator gas. Subsequently, $\mathrm{FIO}_{2}$ was adjusted so that the infant's $\mathrm{SaO}_{2}$ was main- tained between $90 \%$ to $93 \%$. All infants were given a loading dose $(6 \mathrm{mg} / \mathrm{kg})$ of intravenous aminophylline immediately before extubation, followed by a maintenance dose of $2.5 \mathrm{mg} / \mathrm{kg}$ every 12 hours. Infants extubated before day 14 continued to receive the aerosol delivered through a neonatal Aerochamber (Trudell, Canada), which had been modified by removing its one way non-rebreathing valve. This modification has been shown to increase the amount of aerosol delivery. ${ }^{14}$ The face mask of the Aerochamber was replaced with a Laerdal Resuscitation mask (Laerdal, Stavanger, Norway) which has a smaller dead space and tighter fit to the face. The face mask was placed tightly over the infant's face, covering the nose and the mouth during aerosol delivery. After delivery of the second dose, the infant was allowed to breathe into the Aerochamber for 1 minute before the system was removed.

In both groups infants with significant respiratory problems after 14 days of age were given open label systemic dexamethasone, as decided by the attending neonatologist. In our unit treatment with systemic steroids is considered in infants older than 3 weeks of age who remain ventilated with $\mathrm{FIO}_{2}>30 \%$ or breathing spontaneously in an oxyhood with $\mathrm{FIO}_{2}>40 \%$. The two groups were compared for the following outcomes: successful extubation by days 7 and 14 of age; death; oxygen dependency at 28 days of postnatal age and 36 weeks after conception; complications, including hyperglycaemia, hypertension, sepsis confirmed by blood culture, pulmonary air leak (interstitial emphysema, pneumothorax, or pneumomediastinum), periventricular haemorrhage and leucomalacia, retinopathy of prematurity, patent ductus arteriosus, and necrotising enterocolitis; and bacterial colonisation of the airway. Extubation was considered to be successful if the infant was able to breathe spontaneously without the endotracheal tube or assisted ventilation for at least 48 hours without a significant increase in respiratory effort and deterioration in blood gas values. Hyperglycaemia was defined as a blood glucose reading $>7$ $\mathrm{mmol} / \mathrm{l}^{15}$ The number of infants with high blood glucose concentration $>10 \mathrm{mmol} / \mathrm{l}$ was also compared between the two groups. Hypertension was defined as two consecutive readings of systolic or diastolic blood pressure greater than $80 \mathrm{~mm} \mathrm{Hg}$ and $45 \mathrm{~mm} \mathrm{Hg}$, respectively. ${ }^{16}$ Cranial ultrasound scanning was performed at 6,14 , and 28 days of age, and whenever periventricular haemorrhage was suspected clinically. Symptomatic patent ductus arteriosus was treated with intravenous indomethacin after confirmation by echocardiogram. Clinically significant patent ductus arteriosus refractory to indomethacin treatment was closed by surgical ligation. Ophthalmological screening for retinopathy of prematurity was started at 4 weeks of age. Necrotising enterocolitis was diagnosed by the presence of pneumatosis intestinalis or intestinal perforation on abdominal radiograph, or for those requiring surgical intervention, on laparotomy. Tracheal aspirate was obtained for bacterial 
Table 1 Demographic characteristics of study and control infants: numbers are given in mean (SEM) $\neq$ or tabsolute numbers (\%)

\begin{tabular}{|c|c|c|c|}
\hline & $\begin{array}{l}\text { Group } 1 \\
\text { (fluticasone) } n=27\end{array}$ & $\begin{array}{l}\text { Group } 2 \\
\text { (placebo) } n=26\end{array}$ & $p$ Value \\
\hline Gestation (week) $\ddagger$ & $27.9(0.5)$ & $27.1(0.5)$ & $0.275^{\star}$ \\
\hline Birthweight (g) & $993(71)$ & $981(71)$ & $0.906^{\star}$ \\
\hline \multicolumn{3}{|l|}{ Complications of pregnancy $\dagger$} & $0.186^{\star \star}$ \\
\hline Nil & $17(63.0)$ & $23(88.5)$ & \\
\hline Diabetes mellitus & $4(14.8)$ & $1(3.8)$ & \\
\hline Infection & $2(7.4)$ & $1(3.8)$ & \\
\hline Antepartum haemorrhage & $4(14.8)$ & $1(3.8)$ & \\
\hline \multicolumn{3}{|l|}{ Multiple pregnancy $\dagger$} & $0.701^{\star \star}$ \\
\hline Twin & $6(22.2)$ & $8(30.8)$ & \\
\hline Triplet & $2(7.4)$ & $1(3.8)$ & \\
\hline \multicolumn{4}{|l|}{ Rupture of amniotic membrane } \\
\hline Duration $(\mathrm{h}) \ddagger$ & $11.0(1.3)$ & $13.8(2.5)$ & $0.330^{\star}$ \\
\hline Duration > $24 \mathrm{~h} \ddagger$ & $0(0.0)$ & $3(11.5)$ & $0.111^{\star \star}$ \\
\hline Antenatal corticosteroid $\dagger$ & $15(55.6)$ & $13(50.0)$ & $0.897^{\star \star}$ \\
\hline \multicolumn{3}{|l|}{ Mode of delivery $\dagger$} & $0.785^{\star \star}$ \\
\hline Spontaneous vaginal & $12(44.4)$ & $11(42.3)$ & \\
\hline Breech vaginal & $3(11.1)$ & $3(11.5)$ & \\
\hline Forceps & $1(3.7)$ & $0(0.0)$ & \\
\hline Caesaerean section & $11(40.7)$ & $12(46.2)$ & \\
\hline Apgar score at $5 \min <7 \dagger$ & $8(29.6)$ & $8(30.8)$ & $0.835^{\star \star}$ \\
\hline Peak inflation pressure at enrolment $\ddagger$ & $21.2(0.8)$ & $20.5(0.6)$ & $0.463^{\star}$ \\
\hline $\mathrm{PaO}_{2}$ : alveolar $\mathrm{PO}_{2}$ ratio at enrolment $\ddagger$ & $0.19(0.01)$ & $0.19(0.01)$ & $0.630^{\star}$ \\
\hline
\end{tabular}

* Student's $t$ test, ${ }^{\star \star} \chi^{2}$ test.

Table 2 Outcome of study and control infants: values are in absolute number (\%)

\begin{tabular}{|c|c|c|c|c|}
\hline & $\begin{array}{l}\text { Group 1 } \\
\text { (fluticasone) } \\
n=27\end{array}$ & $\begin{array}{l}\text { Group 2 } \\
\text { (placebo) } \\
n=26\end{array}$ & Odds ratio $(95 \% \mathrm{CI})$ & $p$ Value ${ }^{\star}$ \\
\hline \multicolumn{5}{|l|}{ Respiratory status } \\
\hline Extubation within 7 days & $13(48.1)$ & $8(30.8)$ & $2.09(0.59,7.53)$ & 0.311 \\
\hline Extubation within 14 days & $17(63.0)$ & $8(30.8)$ & $3.83(1.06,14.24)$ & 0.038 \\
\hline $\begin{array}{l}\text { Oxygen dependency/death at } 28 \mathrm{~d} \\
\text { Oxygen dependency/death at } 36\end{array}$ & $16(59.3)$ & $17(65.4)$ & $0.77(0.22,2.70)$ & 0.860 \\
\hline post conceptional weeks & $6(22.2)$ & $12(46.2)$ & $0.33(0.08,1.27)$ & 0.121 \\
\hline Mortality & $5(18.5)$ & $9(34.6)$ & $0.43(0.10,1.77)$ & 0.309 \\
\hline \multicolumn{5}{|l|}{ Systemic steroid required after day } \\
\hline 14 & $5(18.5)$ & $8(30.8)$ & $0.51(0.11,2.17)$ & 0.473 \\
\hline \multicolumn{5}{|l|}{ Complications } \\
\hline \multicolumn{5}{|l|}{ Hyperglycaemia } \\
\hline$>7 \mathrm{mmol} / 1$ & $12(44.4)$ & $14(53.8)$ & $0.69(0.20,2.32)$ & 0.682 \\
\hline$>10 \mathrm{mmol} / 1$ & $5(18.5)$ & $6(23.1)$ & $0.76(0.16,3.53)$ & 0.278 \\
\hline Hypertension & $5(18.5)$ & $4(15.4)$ & $1.25(0.23,7.16)$ & 1.000 \\
\hline Pneumothorax & $1(3.7)$ & $2(7.7)$ & $0.46(0.01,9.53)$ & 0.610 \\
\hline $\mathrm{PDA}$ requiring treatment & $17(63.0)$ & $20(76.9)$ & $0.51(0.13,1.97)$ & 0.142 \\
\hline Indomethacin & $13(48.1)$ & $19(73.1)$ & $0.34(0.09,1.24)$ & 0.116 \\
\hline Surgical ligation & $4(14.8)$ & $1(3.8)$ & $4.35(0.38,222.5)$ & 0.351 \\
\hline Necrotising enterocolitis & $7(25.9)$ & $8(30.8)$ & $0.79(0.20,3.05)$ & 0.931 \\
\hline Periventricular haemorrhage & $9(33.3)$ & $6(23.1)$ & $1.67(0.43,6.67)$ & 0.601 \\
\hline Grade III/IV & $3(11.1)$ & $3(11.5)$ & $0.96(0.12,7.92)$ & 1.000 \\
\hline Grade I/II & $6(22.2)$ & $3(11.5)$ & $2.19(0.40,15.04)$ & 0.467 \\
\hline Periventricular leucomalacia & $3(11.1)$ & $1(3.8)$ & $3.13(0.23,170.49)$ & 0.610 \\
\hline Retinopathy of prematurity & $6(22.2)$ & $4(15.4)$ & $1.57(0.32,8.63)$ & 0.728 \\
\hline Stage I & $4(14.8)$ & $2(7.7)$ & $2.09(0.27,24.84)$ & 0.669 \\
\hline Stage II & $2(7.4)$ & $2(7.7)$ & $0.96(0.06,14.24)$ & 1.000 \\
\hline \multicolumn{5}{|l|}{ Culture proved sepsis } \\
\hline First 14 days & $1(3.7)$ & $0(0.0)$ & Undefined & 1.000 \\
\hline Before hospital discharge & $5(18.5)$ & $7(26.9)$ & $0.62(0.13,2.72)$ & 0.687 \\
\hline $\begin{array}{l}\text { Pathogens isolated from tracheal } \\
\text { aspirate }\end{array}$ & $11(40.7)$ & $9(34.6)$ & 0.773 & \\
\hline
\end{tabular}

and fungal culture immediately before the first dose of aerosol, and at 3, 5, 7 and 14 days of age.

Static respiratory system compliance (Crs) and resistance (Rrs) were measured immediately before the start of aerosol treatment, and repeated on days 3,7 , and 14 in infants who remained intubated and ventilated. Both Crs and Rrs were measured using a SensorMedics Pulmonary Cart (SensorMedics Inc., Yorba Linda, CA, USA) using the passive flowvolume technique. ${ }^{17}$ The measurement was carried out using a pneumotachograph (Hans Rudolph Inc., USA) with a small dead space $(1.8 \mathrm{ml})$ connected to the endotracheal tube. A breath was accepted for analysis only when the occlusion pressure reached a stable plateau. In each measurement Crs and Rrs were obtained from the mean values of at least 10 acceptable breaths with a coefficient of variation of less than $10 \%$.

The particle size distribution of the fluticasone aerosol was estimated by collecting the contents of 10 actuations of the metered dose inhaler into an Anderson Cascade Impactor operating at $28.3 \mathrm{1} / \mathrm{min}$. The amount of fluticasone collected at each stage of the Impactor was assayed spectroscopically (Hitachi Spectrophotometer, Trudell, Canada). The experiment was repeated by actuating the inhaler into an MV15s Aerochamber connected to the Y-connector of a continuous flow ventilator circuit similar to that used in the infants. The aerosol was collected into the impactor after passing through an endotracheal tube connected to the exit of the Aerochamber. The test was carried out using endotracheal tubes of two different sizes: $2.5 \mathrm{~mm}$ and $3.0 \mathrm{~mm}$ internal diameter. Each experiment was repeated six times and the mass median aerodynamic diameter (MMAD) and geometric standard deviation (GSD) calculated.

The dose of fluticasone available at the end of each size of endotracheal tube was measured by collecting single doses in unit-dose collection tubes and assaying the drug as above.

Comparison between the two groups was made using the non-paired Student's $t$ test for continuous variables, and the $\chi^{2}$ test for rates and proportions. Serial measurements within the same group were compared by repeated measures analysis of variance (ANOVA), followed by the Bonferroni $t$ test when the ANOVA test showed a significant difference. Between group comparison of serial changes in lung mechanics with time was made by multivariate analysis using unbalanced repeated measures models with first order autoregressive covariance matrices (BMDP/Dynamic Program 5V, release 7, BMDP Statistical Software Inc., Los Angeles, CA, USA). Wald statistics were used to check the significance of the differences between the two groups over time.

\section{Results}

The demographic characteristics of the infants are given in table 1 . The two groups were similar in their perinatal characteristics, including antenatal exposure to corticosteroids. None of the infants in either group was suspected of having sepsis on clinical grounds, and their initial blood cultures were all negative.

Table 2 gives the outcomes of the infants. Significantly more infants in group 1 were successfully extubated by 14 days of life. Other outcome measures, including successful extubation by day 7 , death before discharge, and oxygen dependency or death by 28 days of life or 36 weeks after conception did not differ significantly between the two groups, although there seemed to be a trend favouring those receiving inhaled fluticasone.

The complications the infants developed before discharge from the hospital are given in table 2. There were no significant differences between the two groups in the occurrence of 
Table 3 Crs and Rrs of infants who remained intubated up to 14 days of age: values are given as mean (SEM)

\begin{tabular}{|c|c|c|c|c|c|c|}
\hline & $n$ & Before treatment & Day 3 & Day 7 & Day 14 & $p$ Value* \\
\hline \multicolumn{7}{|l|}{ Crs/kg (ml/kpa/kg): } \\
\hline Group 2 (placebo) & 14 & $5.08(0.28)$ & $6.76(0.42)$ & $8.65(0.54)$ & $9.77(0.71)$ & $<0.0001 \ddagger$ \\
\hline \multicolumn{7}{|l|}{$\operatorname{Rrs}(\mathrm{kpa} / \mathrm{l} / \mathrm{s})$ : } \\
\hline Group 1 (fluticasone) & 9 & $49.67(1.96)$ & $34.18(2.45)$ & $30.02(3.38)$ & $23.85(4.68)$ & $<0.0001+$ \\
\hline Group 2 (placebo) & 14 & $50.98(2.77)$ & $42.69(4.07)$ & $38.53(5.17)$ & $36.71(5.52)$ & $0.0003 \delta$ \\
\hline
\end{tabular}

$\star$ One way repeated measures ANOVA.

Pairwise multiple comparison with Bonferroni's method $(\mathrm{p}<0.05)$ :

† Day 14 and day $7>$ day $3>$ before treatment.

$\ddagger$ Before treatment $>$ day 3 , day 4 and day 14 .

$\S$ Before treatment $>$ day 7 and day 14 .

complications attributable to corticosteroid treatment, including hyperglycaemia, hypertension, or sepsis. There were also no significant differences in the occurrence of pulmonary air leak, periventricular haemorrhage or leucomalacia, retinopathy of prematurity, patent ductus arteriosus, or necrotising enterocolitis. The tracheal aspirate obtained before aerosol treatment was sterile in all except two infants (Staphylococcus aureus and Enterobacter $\mathrm{spp}$ ) in the treatment group and one infant ( $S$ aureus) in the control group. After the start of aerosol treatment, pathogens were isolated from the tracheal aspirate of 20 infants whose culture before treatment was negative. These included 11 infants in the treatment group (nine $S$ aureus, one Enterobacter spp, one Klebsiella $\mathrm{spp}$ ) and nine infants in the placebo group (eight $S$ aureus, one Enterobacter spp). The difference was not significant.

Serial static Crs and Rrs were measured successfully in nine infants in group 1 and 14 infants in group 2 who remained intubated at 14 days of age. Both parameters were similar between the two groups before the start of aerosol treatment (Crs: mean[SEM] $5.11[0.23] \mathrm{ml} / \mathrm{kPa} / \mathrm{kg}$ vs $5.08[0.21] \mathrm{ml} / \mathrm{kPa} / \mathrm{kg}$, $\mathrm{p}=0.945 ;$ Rrs: $49.62[1.13] \mathrm{kPa} / 1 /$ second $v s$ $50.99[2.04] \mathrm{kPa} / \mathrm{l} / \mathrm{second}, \mathrm{p}=0.735)$. Subsequently, Crs and Rrs in both groups improved progressively with age (table 3 ). The serial changes in both parameters across time were greater in group 1, although only the difference in Crs was significant between the two groups (fig 1).

The aerosol particles collected directly from the MDI had a mean (SEM) MMAD of 2.62 $(0.02) \mu \mathrm{m}$ with a mean (SEM) GSD of 1.72 (0.01). After passing through an MV15s Aerochamber and a $2.5 \mathrm{~mm}$ endotracheal tube, the mean (SEM) MMAD and GSD were 1.85 $(0.07) \mu \mathrm{m}$ and $2.31(0.18)$, respectively. When the experiment was repeated using a $3.0 \mathrm{~mm}$ endotracheal tube, the mean (SEM) MMAD and GSD were $1.70(0.04) \mu \mathrm{m}$ and $1.99(0.13)$, respectively. The dose of fluticasone aerosol available at the end of the endotracheal tube was greater for the $3.0 \mathrm{~mm}$ tube compared with the $2.5 \mathrm{~mm}$ tube $(98.9$ [13.7] $\mu \mathrm{g}$ vs 83.6[8.7] $\mu \mathrm{g}$, $\mathrm{p}=0.043$ ), with the mean (SEM) proportion of particles having diameters $<5.8 \mu \mathrm{m} \quad 89.8$ (1.65)\% with the $2.5 \mathrm{~mm}$ endotracheal tube, and $94.3(0.85) \%$ with the $3.0 \mathrm{~mm}$ endotracheal tube $(\mathrm{p}=0.037)$.
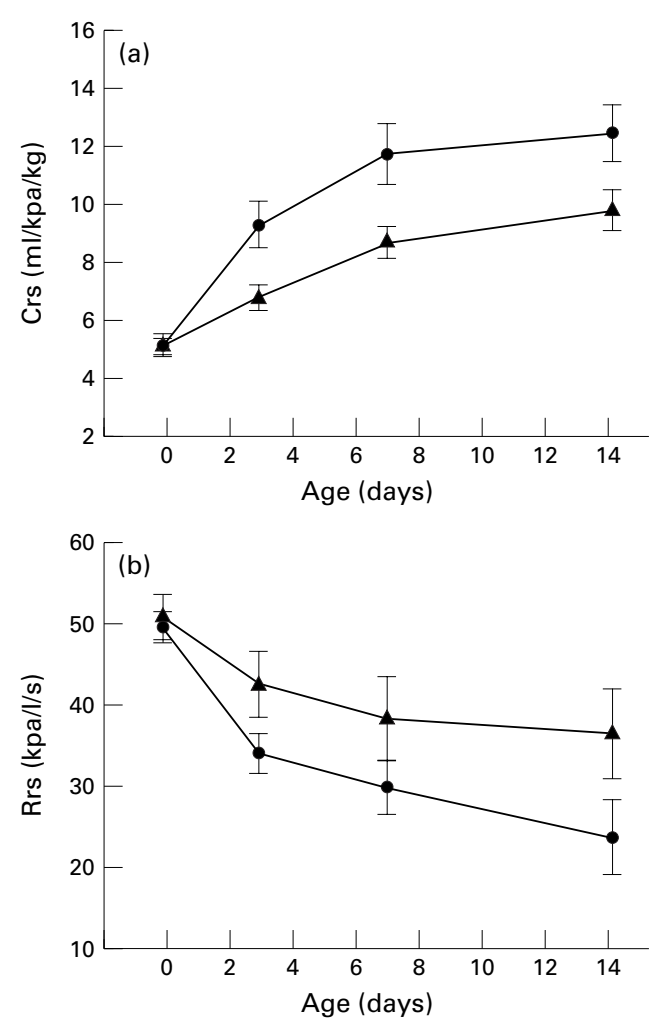

Figure 1 Curves plotting (A) Crs/kg and (B) Rrs over

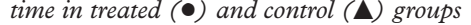

(mean(SEM)). Slope of curves shows that the

improvement in Crs over time was significantly greater in the treated group (linear interaction, $p=0.0006$, quadratic equation, $p=0.0043$ ) whereas that in Rrs did not differ significantly between the two groups (linear interaction, $p=$ 0.082 , quadratic interaction, $p=0.640$ ).

\section{Discussion}

Treatment with systemic dexamethasone within the first day of life can facilitate earlier extubation ${ }^{35}$ and reduce the incidence of CLD in ventilated preterm infants with RDS. ${ }^{4}$ Despite these potential benefits, the early use of systemic corticosteroids in neonates is not supported by existing evidence because of its adverse side effects. ${ }^{46718-27}$ Of particular concern is its association with infection ${ }^{723}$ and impaired brain growth. ${ }^{1824}$ A significant increase in infection rate has been observed in infants given systemic dexamethasone on the first day of life. ${ }^{4}$ In a recent randomised trial comparing systemic dexamethasone started at 2 weeks and 4 weeks of age for the treatment of ventilator dependent preterm infants, early treatment was associated with a higher incidence of nosocomial infection. ${ }^{7}$ In animal studies corticosteroids have been shown to 
have a deleterious effect on the developing brain. ${ }^{24-25}$ In preterm newborn infants a 28 day course of systemic dexamethasone started on day 1 of life has been associated with a higher incidence of neuromotor dysfunction. ${ }^{6}$

The complications of corticosteroids may potentially be minimised by using the medication as an aerosol: because this is directly administered to the lungs, it requires a significantly smaller dose than its systemic counterparts. ${ }^{8-11}$ However, one major difficulty in using aerosol medications in small infants is the scanty amount of aerosol that can reach the lower respiratory tract. Previous workers have shown that only $0.1 \%$ to $1.2 \%$ of the nominal dose can be deposited in the lungs of ventilated infants. ${ }^{28-30}$ To maximise the amount of lung deposition, we used fluticasone delivered by MDI with a spacer device in this study. Among the aerosol delivery devices currently available for small infants, the MDI-spacer device is better than the jet or ultrasonic nebuliser at delivering corticosteroids because the medication is formulated as a suspension and cannot be effectively nebulised. ${ }^{31} 32$

As shown in our particle size study, the MDI aerosol contains particles that are well within the respirable range of 1 to $5 \mu \mathrm{m}$ at the exit of the delivery system. Compared with other inhaled preparations, fluticasone propionate has the advantage of being a more potent antiinflammatory agent than dexamethasone or beclomethasone. ${ }^{32-34}$ It is also available in a concentrated formulation, which allows a relatively large dose of $500 \mu \mathrm{g}$ to be administered with only two actuations. In the pilot phase of the study we showed that the current dose of fluticasone suppresses the hypothalamicpituitary-adrenal axis, confirming that a pharmacologically active dose of the medication has reached the lungs. ${ }^{35}$

Our findings showed that a 14 day course of inhaled fluticasone started at around 24 hours of age was associated with a significantly higher success rate in extubation within the first two weeks of life. The treated infants showed a better improvement in lung compliance than those in the placebo group. Although not significant, infants given inhaled steroids also showed a trend towards a lower requirement for open label systemic steroids and developed less CLD. The treatment was not associated with any increase in steroid induced side effects such as hypertension, hyperglycaemia, or sepsis. Bacterial colonisation of the airway was also similar between the treated and control infants.

Our findings thus provide the first piece of evidence that early treatment with fluticasone delivered by MDI may be beneficial to ventilated preterm infants with RDS. Like the early studies on the early use of systemic dexamethasone, ${ }^{35}$ our study failed to show any significant long term benefit of the treatment, possibly because of the relatively small sample size. Neither was it designed to investigate the long term complications of the early use of inhaled steroids. These issues could only be unravelled by a large scale randomised study. ${ }^{46}$ Given its potential benefits, further exploration of the use of inhaled steroids in preterm infants is warranted.

The study was partly supported by a grant from GlaxoWellcome (Hong Kong). We thank Mr Eric Wong, Centre for Clinical Trials and Epidemiological Research, The Chinese University of Hong Kong, for statistical assistance, and $\mathrm{Mr}$ Rodney Rhem, Department of Medicine, McMaster University Medical Centre, for his assistance in particle size measurement.

1 Merritt TA, Cochrane CG, Holcomb K, Bohl B, Hallman M, Strayer D. Elastase and alpha 1-proteinase inhibitor $\mathrm{M}$, Strayer $\mathrm{D}$. Elastase and alpha 1 -proteinase inhibitor activity in tracheal aspirate during respir

2 Murch SH, MacDonald TT, Wood CB, Costeloe KL. Tumour necrosis factor in the bronchoalveolar secretions of infants with the respiratory distress syndrome and the effect of dexamethasone treatment. Thorax 1992;47:44-7.

3 Yeh TF, Torre JA, Rastogi A, Anyebuno MA, Pildes RS. Early postnatal dexamethasone therapy in premature infants with severe respiratory distress syndrome: a double blind controlled study. Pediatrics 1990;117:273-82.

4 Yeh TF, Lin YJ, Hsieh WS, et al. Early postnatal dexamethasone therapy for the prevention of chronic lung disease in preterm infants with respiratory distress syndrome: a multicenter clinical trial. Pediatrics 1997;100:e3

5 Shinwell ES, Karplus M, Zmora E. Failure of early postnatal dexamethasone to prevent chronic lung disease in infants with respiratory distress syndrome. Arch Dis Child 1996; 74:F33-F7.

6 Yeh TF, Lin YJ, Huang CC, et al. Early dexamethasone therapy in preterm infants: a follow-up study. Pediatrics 1998;101:e7

7 Papile L-A, Tyson JE, Stoll BJ, et al. A multicenter trial of two dexamethasone regimens in ventilator-dependent premature infants. N Engl F Med 1998;338:1112-8.

8 LaForce WR, Brudno DS. Controlled trial of beclomethasone dipropionate by nebulization in oxygen- and

9 Cloutier MM. Nebulized steroid therapy in bronchopulmonary dysplasia. Pediatr Pulmonol 1993;15:111-6.

10 Dunn M, Magnani L, Anaka R, Kirpalani H. Nebulized steroids for bronchopulmonary dysplasia (BPD) - a randomized, double-blind cross-over study. Pediatr Res 1991;201A.

11 Dunn MS, Magnani L, Belaide M. Inhaled corticosteroids in severe bronchopulmonary dysplasia (BPD). Pediatr Res 1989;25:213A

12 Yuksel B, Greenough A. Randomised trial of inhaled steroids in preterm infants with respiratory symptoms at follow up. Thorax 1992;47:910-3.

13 Giep T, Raibble P, Zuerlein T, Schwartz ID. Trial of beclomethasone dipropionate by metered-dose inhaler in ventilator-dependent neonates less than 1500 grams. Am $\mathcal{f}$ Perinatol 1996;13:5-9.

14 Fok TF, Lam K, Chan CK, et al. Aerosol delivery to non-ventilated infants by metered-dose inhaler: should a valved spacer be used? Pediatr Pulmonol 1997;24:204-12.

15 Cornblath M, Schwartz R. Disorders of carbohydrate metabolism in infancy. 2nd edn. Philadelphia: WB Saunders, 1976.

16 Lieberman J. Clinical Pediatric Nephrology. Philadelphia: JB Lippincott, 1976.

17 Le Souëf PN, England SJ, Bryan AC. Passive respiratory mechanics in newborns and children. Am Rev Respir Dis 1984;129:553-6.

18 Jones R, Wincott E, Elbourne D, Grant A. Controlled trial of dexamethasone in neonatal chronic lung disease: a 3-year follow-up. Pediatrics 1995;96:897-906.

19 Le Souëf PN, England SJ, Bryan AC. Passive respiratory mechanics in newborns and children. Am Rev Respir Dis 1984;129:553-6.

20 Avery GB, Fletcher AB, Kaplan M, Brudno DS. Controlled trial of dexamethasone in respirator-dependent infants with bronchopulmonary dysplasia. Pediatrics 1985;75:10611 .

21 Mammel MC, Fiterman C, Coleman M, Boros SJ. Short-term dexamethasone therapy for bronchopulmonary dysplasia: acute effects and a 1-year follow-up. Dev Pharmacol Ther 1987; 10:1-11.

22 Cummings JJ, D’Eugenio DB, Gross SJ. A controlled trial of dexamethasone in preterm infants at high risk for bronchopulmonary dysplasia. $N$ Engl $f^{\prime}$ Med 1989;320:1505-10.

$23 \mathrm{Ng}$ PC. The effectiveness and side effects of dexamethasone in preterm infants with bronchopulmonary dysplasia. Arch Dis Child 1993;68:330-6.

24 Ng PC, Thomson MA, Dear PRF. Dexamethasone and infection in preterm babies: a controlled study. Arch Dis Child 1990;65:54-8.

25 Weichsel ME Jr. The therapeutic use of glucocorticoid hormones in the perinatal period: potential neurologic hazards. Ann Neurol 1977;2:364-6.

26 Cotterrell M, Balazs R, Johnson AL. Effects of corticosteroid on the biochemical maturation of rat brain: postnatal cell formation. F Neurochem 1972;19:2151-67.

27 O'Shea TM, Kothadia JM, Klinepeter KL, Goldstein DJ, Jackson B, Dillard RG. Follow-up of preterm infants Jackson $\mathrm{B}$, Dillard RG. Follow-up of preterm infants
treated with dexamethasone for chronic lung disease. $A m \mathcal{F}$ Dis Child 1993; 147:658-61. 
28 Fok TF, Dolovich M, Gray S, et al. Efficiency of aerosol medication delivery from a metered dose inhaler versus jet nebuliser in infants with bron

29 Fok TF, Al-essa M, Monkman S, et al. Pulmonary deposition of albuterol aerosol delivered by metered-dose inhaler, jet nebulizer and ultrasonic nebulizer in mechanicall ventilated rabbits. Pediatr Res 1997;42:721-7.

30 O'Callaghan C, Hardy J, Stammers J, Stephenson TJ, Hull D. Evaluation of techniques for delivery of steroids to lungs of neonates using a rabbit model. Arch Dis Child 1992;67:20-4.

31 Rozycki HJ, Bryon PR, Dailey K, Gutcher GR. Evaluation of a system for the delivry of inhaled beclomethasone dipropionate to intubated neonates. Pediatrics 1994;81:607-706.
32 Kamada AK, Szefler SJ. Inhaled therapy in infants: why not nebulize glucocorticoids? Pediatr Pulmonol 1992;13:198-9.

33 Dahl R, Lundback B, Malo JL, et al. A dose-ranging study of fluticasone propionate in adult patients with moderate asthma. International Study Group. Chest 1993;104:1352-

34 Barnes NC, Marone G, Di Maria GU, Visser S, Utama I, Payne SL. A comparison of fluticasone propionate, $1 \mathrm{mg}$ daily, with beclomethasone dipropionate, $2 \mathrm{mg}$ daily, in the treatment of severe asthma. International Study Group. Eur Respir F 1993;6:877-85.

$35 \mathrm{Ng}$ PC, Fok TF, Wong GWK, et al. Pituitary-adrenal suppression in preterm, very low birth weight infants after inhaled fluticasone propionate treatment. $\mathcal{F}$ Clin Endocrinol Metab 1998;83:2390-3. 